\title{
Symptoms of mental health problems among Italian adolescents in 2017-2018 school year: a multicenter cross-sectional study
}

Francesco Donato ${ }^{1}$, Maria Triassi ${ }^{2}$, llaria Loperto², Alessia Maccaro ${ }^{3}$, Sara Mentasti ${ }^{1}$, Federica Crivillaro ${ }^{1}$, Antonella Elvetico ${ }^{1}$, Elia Croce $^{4}$ and Elena Raffetti ${ }^{5^{*}}$ (i)

\begin{abstract}
Background: Identifying individual and contextual factors that influence adolescent well-being is a research priority. This study aimed to assess the prevalence of symptoms of mental health problems and some related factors in Italian adolescents in 2017-2018.

Methods: The present study was a cross-sectional survey among 3002 students aged 15-16 years who resided in two Italian provinces, in North and South Italy. Symptoms of mental health problems were assessed using the SDQ and CES-DC, and students' risk-taking behaviors and school climate perception were assessed. All information was collected anonymously. Logistic regression models were used to assess the associations of tobacco and alcohol use, screen time, bullying, and school climate with symptoms of mental health problems.

Results: One student out of five reported symptoms of mental health problems, with a more than double proportion among girls than boys ( $28.7 \%$ vs $10.4 \%$ with depressive symptoms, respectively). Thirty percent and $40 \%$ of students smoked tobacco or drank alcoholic beverages at least once in the past month, and more than $40 \%$ reported being victims or authors of bullying in the past 6 months. Smoking behavior, alcohol consumption, screen time, bullying, and negative school climate had 1.2- to 3.3-fold increased odds of symptoms of mental health problems without substantial differences between sexes and geographical areas.
\end{abstract}

Conclusions: Tobacco and alcohol use, screen time, bullying, and school climate were independently associated with symptoms of mental health problems in a large sample of 15-16-year-old Italian adolescents without substantial gender and geographical differences.

Keywords: Mental health, Risk factors, Behaviors, Social context

\footnotetext{
* Correspondence: elena.raffetti@ki.se

${ }^{5}$ Epidemiology and Public Health Intervention Research Group (EPHIR),

Department of Global Public Health, Karolinska Institutet, Solnavägen 1 E,

11365 Stockholm, Sweden

Full list of author information is available at the end of the article
}

C The Author(s). 2021 Open Access This article is licensed under a Creative Commons Attribution 4.0 International License, which permits use, sharing, adaptation, distribution and reproduction in any medium or format, as long as you give appropriate credit to the original author(s) and the source, provide a link to the Creative Commons licence, and indicate if changes were made. The images or other third party material in this article are included in the article's Creative Commons licence, unless indicated otherwise in a credit line to the material. If material is not included in the article's Creative Commons licence and your intended use is not permitted by statutory regulation or exceeds the permitted use, you will need to obtain permission directly from the copyright holder. To view a copy of this licence, visit http://creativecommons.org/licenses/by/4.0/. The Creative Commons Public Domain Dedication waiver (http://creativecommons.org/publicdomain/zero/1.0/) applies to the data made available in this article, unless otherwise stated in a credit line to the data. 


\section{Background}

The prevalence of depression and anxiety disorders is one of the main causes of disability-adjusted life years among adolescents and young adults [1]. In 2018, depressive disorders affected $3.6 \%$ of adolescents (15-19 years of age) in Italy, with a preponderance of females (4.7\% females and $2.5 \%$ males) [2]. Adolescence is a crucial period for brain development, the onset of risktaking behaviors, and mental health problems [3]. Although prevention of depression and other psychiatric disorders is a key point in preventive medicine strategies, the underlying causal pathway that leads to the onset of mental health problems among adolescents is complex and involves the interplay of several factors such as family history of depression, exposure to psychosocial stress, developmental factors, sex hormones, and psychosocial adversities [3].

Substance use, particularly tobacco smoking, use of alcohol, cannabis, and other illicit drug, is considered an important determinant of subsequent development of mental health problems among adolescents $[4,5]$. Social context along with school context may influence the onset of psychiatric disorders due to negative interactions with peers [3] or school failure [6, 7]. Victimization from bullying is another risk factor for mental health problems and, conversely, mental health problems may predispose adolescents to bullying victimization $[8,9]$. The use of technologies during leisure time, including television, social media, videogames, and the internet has rapidly increased among adolescents in the 2000s. Screen time has been associated with mental health problems in adolescence in some studies, although overall findings are inconsistent, with substantial differences according to types of screen time and non-linear time-varying associations [10, 11].

Although prevention of adolescents' mental health problems is of the utmost importance, present evidence of the role of modifiable risk factors is uncertain. Differences in time period and societal context may explain, at least partly, the discrepancies on factors influencing adolescents' mental health between studies, when also considering the rapid changes in adolescents' behaviors, particularly as regards the use of technology devices and social relationships, in the 2000 s.

The present study aimed to evaluate the prevalence of symptoms of mental health problems and related risk factors in Italian high school students in 2017-2018, few years before the beginning of the COVID-19 pandemic.

\section{Materials and methods}

\section{Study design}

The Be Teen project is an epidemiological study set up to investigate the determinants of symptoms of mental health problems among high school students in Brescia and Naples provinces; two different areas of Italy in term of geographical location, social interaction, and industrialization.

Naples and Brescia provinces are densely populated metropolitan areas located in the south and north part of Italy, respectively. Naples compared to Brescia province is a less industrialized area and has a higher prevalence of tobacco smoking (26.5\% vs. $22.6 \%)$, obesity (13.8\% vs. $7.5 \%)$, depressive symptoms (7.6\% vs $5.8 \%)$, and unemployment (44.2\% vs $29.5 \%)$ but lower alcohol consumption $(44.4 \%$ vs. $60.8 \%)$ in the adult population, according to a recent national survey (2016-2019) [12].

This study has applied the same methodology as the Swedish Kupol study [13] and includes both a crosssectional and a prospective cohort study. The present paper reports the results of the cross-sectional survey, whereas those of the cohort study will be shown at the end of the follow-up, in 2022. The study was conducted in accordance with the guidelines of the Declaration of Helsinki and the principles of Good Clinical Practice. It was approved by the Ethics Committee of the Brescia province (Dnr: 2761-04-10-2017) and ethics Committee "Carlo Romano", University of Naples "Federico II" (Dnr: 272/17).

The schools were recruited in 2017. Inclusion criteria for the institutes were to be located in Brescia and $\mathrm{Na}$ ples provinces, to include at least 20 students per school class and at least 5 classes for 10th grade. For each institute, 10th-grade students, resident in the province, aged 15-16 years and able to understand every item of the questionnaire were eligible. The survey was carried out between November 2017 and November 2018. The flowchart of the selection of schools and students and their participation is shown in Fig. 1. Nineteen of the 39 public and private schools in Brescia Province were considered eligible and contacted, and 15 of them (79\%) adhered to the project. Two thousand three hundred sixteen students attending the selected schools were invited to participate: 2166 of them accepted (93\%) and 1962 provided complete data. In Naples city and province, a random sample of eligible school was invited. Among them, 10 adhered to the project (67\%), and 1221 out of 1675 students invited (73\%) accepted to enter the survey: 1040 of them provided complete data. Overall, a total of 3002 students were included in the present study: 1962 from Brescia and 1040 from Naples Province.

\section{Questionnaire}

The school personnel could choose between computerand paper-based anonymous questionnaires. The questionnaire consisted of 27 items investigating age and gender, parental education, mental health, school climate, tobacco smoking and alcohol consumption, bullying, and use of technology devices during leisure time 


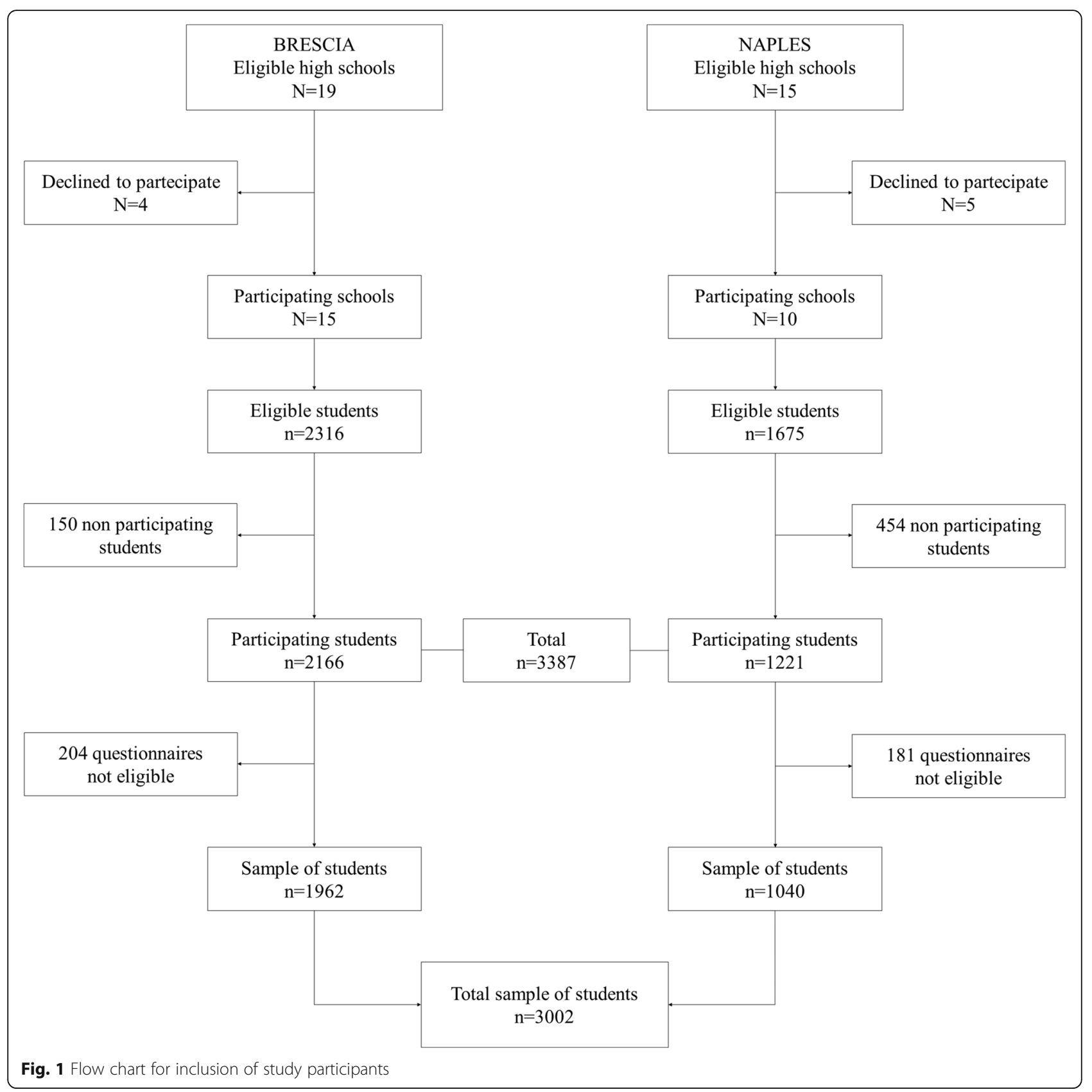

(television, social networks, web navigation, videogames).

\section{Symptoms of mental health problems}

Mental health was evaluated through two scales for psychological wellness: CES-DC (Center for Epidemiological Studies-Depression Scale for Children) and SDQ (Strengths and Difficulties Questionnaire). The CES-DC is a 20 -item self-administered questionnaire that investigates the prevalence of symptoms linked to depression during the past 7 days [14]. The score ranges from 0 to
60 and a cut-off score of 30 or higher indicates the presence of depressive symptoms.

The SDQ is a 25-item self-report questionnaire evaluating different psychological symptoms and behaviors in the past 6 months [15]. It consists of 5 subscales, each one of 5 items: emotional symptoms, conduct problems, hyperactivity-inattention, peer problems, and prosocial behavior. The prosocial behavior subscale score reflects psychological strengths, whereas the total difficulties score is the sum of the other subscales' scores. SDQ screening for mental health problems uses the total difficulties scale. Dichotomizing the SDQ score, we 
considered 16 as the cut-off for detecting symptoms of mental health problems. In addition, we evaluated two SDQ sub-scores: the internalizing and the externalizing scores, the former concerning peer relationship problems and emotional symptoms, and the latter behavior problems and hyperactivity/inattention [16]. A score above 9 and above 11 was considered as the threshold for internalizing and externalizing scales, respectively.

Both CES-DC and SDQ have been internationally validated as screening questionnaires for symptoms of mental health disorders. In this sample, the Cronbach alpha was $90.7 \%$ and $78.4 \%$ for CES-DC and SDQ, respectively.

\section{Risk factors for mental health}

Students were considered current tobacco smokers if they had smoked at least one cigarette in the past 30 days and perceived tobacco dependence if they have ever perceived tobacco dependence. Alcohol consumption and perceived drunkenness were both investigated in the past month: the former as drinking at least one alcoholic beverage, and the latter as the perception of drunkenness. The legal ages for tobacco use and alcohol consumption are 18 and 16 years, respectively, in Italy.

The use of technology devices during leisure time was investigated as hours spent during the weekdays and weekends in watching television, navigating the web, playing videogames, and using social networks. For each type of screen time, mean daily time was considered. Bullying was evaluated through questions about general, psychological, and physical bullying in the past 6 months, as a victim or author. The school climate was investigated through the PESOC questionnaire (Pedagogical and Social Climate of a school) [17]. It contains 53 positive items on the school context and assesses students' perceptions of 8 dimensions regarding their school: expectations, perception of teacher norms, teachers' support, teaching activities, student participation, school environment, school and home, and school management [17]. The score ranged from 1 to 4 for each domain, a mean score of PESOC item sum of 2.5 was considered as the cut-off for negative school climate.

\section{Other covariates}

Parental education was defined as the highest educational degree achieved by any parent (elementary school, high school, and university) and included as a possible confounder.

\section{Statistical analysis}

A descriptive analysis of the characteristics of the sample was performed. Separate analyses were conducted for gender and center. Categorical variables were reported as proportions and continuous variables as means and standard deviations. The sample characteristics were compared by gender and center using common statistical tests: the Wilcoxon rank test for continuous variables, due to non-normal distribution, and the chisquare test for proportions. For the ordinal screen time variables, a test for linear trend was performed.

The associations between risk factors and mental health problems were evaluated using logistic regression models with symptoms of mental health problems, according to CES-DC and SDQ scales and subscales, as the dichotomous dependent variable. Each risk factor was examined using three models: unadjusted model, adjusted model A, and adjusted model B. Adjusted model A is a logistic regression model that accounts for possible confounders, including sex, parental education, tobacco smoking, social networks, and bullying victimization. Adjusted multilevel model B includes model A confounders and clusters on institutes and centers. The odds ratios (ORs) were computed as measures of association with their 95\% confidence intervals (95\% CIs). For all the analyses, two-tailed statistical tests were performed at the level of 0.05 . All the statistical analyses were performed using the Stata software version 14.0 (StataCorp, College Station, TX, USA).

\section{Results}

A total of 3002 adolescents were included, $55.9 \%$ females, with a mean age of 15.2 years old. The characteristics of the students by gender are set out in Table 1 . $46.5 \%$ of the students had at least one parent with a high school degree and $38.6 \%$ a university degree. $30.4 \%$ of the students reported current smoking, and 13\% perception of having been tobacco dependent. Alcohol consumption was more prevalent than tobacco smoking, as it was reported by $40.4 \%$ of students, especially among males (46.5\%). Regarding screen time, students used social networks more often than other technology tools. The daily time for social media equal or higher than $4 \mathrm{~h}$ was referred by $45.1 \%$ of the students, with an overall higher exposure in females than males. Bullying was reported by about $40 \%$ of the students $(41.4 \%$ victims and $39.8 \%$ authors), with a higher proportion of victims among females than males $(43.7 \%$ vs $38.4 \%)$, whereas more males than females referred to have been authors (48.4\% vs $33.1 \%)$. Finally, one out of three students had a negative perception of their school climate. Students with CES-DC and SDQ with symptoms of mental health problems were $20.8 \%$ and $17.8 \%$, respectively, with a higher proportion of females than males $(28.7 \%$ vs $10.4 \%$ for CES-DC and $22.3 \%$ vs $12.1 \%$ for SDQ, respectively). The two scores were highly related with 0.739 linear correlation coefficient between them.

Supplementary Table 1 shows the characteristics of students separated between centers. The prevalence of 
Table 1 Characteristics of students according to gender

\begin{tabular}{|c|c|c|c|c|}
\hline & $\begin{array}{l}\text { Females } \\
\text { n (\%) }\end{array}$ & $\begin{array}{l}\text { Males } \\
\mathrm{n}(\%)\end{array}$ & $\begin{array}{l}\text { All } \\
\text { n (\%) }\end{array}$ & $p$ value $^{a}$ \\
\hline Total subjects & $1679(55.9)$ & $1323(44.1)$ & 3002 & \\
\hline \multicolumn{5}{|l|}{ Geographical area } \\
\hline Brescia & $1056(62.9)$ & $906(68.5)$ & $1962(65.4)$ & \\
\hline Naples & $623(37.1)$ & $417(31.5)$ & $1040(34.6)$ & 0.002 \\
\hline Mean age (SD), years & $15.2(0.4)$ & $15.2(0.4)$ & $15.2(0.4)$ & \\
\hline \multicolumn{5}{|l|}{ Higher parental education, years } \\
\hline$\leq 8$ & $249(15.3)$ & $180(14.4)$ & $429(14.9)$ & \\
\hline $9-13$ & $793(48.8)$ & $546(43.5)$ & $1339(46.5)$ & \\
\hline$\geq 14$ & $582(35.8)$ & $528(42.1)$ & 1110 (38.6) & \\
\hline \multicolumn{5}{|l|}{ Substance use§ } \\
\hline Tobacco smoking & $529(31.5)$ & $383(29.0)$ & $912(30.4)$ & 0.142 \\
\hline Perceived tobacco dependence & $239(14.7)$ & $140(10.8)$ & $379(13.0)$ & 0.002 \\
\hline Alcohol consumption & $586(35.6)$ & $603(46.5)$ & $1189(40.4)$ & $<0.001$ \\
\hline Perceived drunkenness & $98(6.0)$ & $107(8.4)$ & $205(7.1)$ & 0.015 \\
\hline \multicolumn{5}{|l|}{ Screen time } \\
\hline \multicolumn{5}{|l|}{ TV } \\
\hline $0-1 \mathrm{~h}$ & $835(51.0)$ & $786(61.4)$ & $1621(55.6)$ & \\
\hline $2-3 \mathrm{~h}$ & $448(27.4)$ & 302 (23.6) & $750(25.7)$ & \\
\hline$\geq 4 \mathrm{~h}$ & $353(21.6)$ & $192(15.0)$ & $545(18.7)$ & $<0.001$ \\
\hline Mean (SD), h & $2.09(1.52)$ & $1.73(1.43)$ & 1.93 (1.49) & \\
\hline \multicolumn{5}{|l|}{ Social networks } \\
\hline $0-1 \mathrm{~h}$ & $324(19.7)$ & $570(44.0)$ & $894(30.4)$ & \\
\hline $2-3 \mathrm{~h}$ & 393 (23.9) & $328(25.4)$ & $721(24.5)$ & \\
\hline $4-5 \mathrm{~h}$ & $419(25.4)$ & 235 (18.2) & $654(22.3)$ & \\
\hline$\geq 6 \mathrm{~h}$ & $511(31.0)$ & $160(12.4)$ & $671(22.8)$ & $<0.001$ \\
\hline Mean (SD), h & $3.8(2.1)$ & $2.5(1.9)$ & $3.27(2.1)$ & \\
\hline \multicolumn{5}{|l|}{ Web navigation } \\
\hline $0-1 \mathrm{~h}$ & $1211(74.2)$ & $1050(82.4)$ & 2261 (77.8) & \\
\hline $2-3 h$ & 258 (15.8) & 149 (11.7) & $407(14.0)$ & \\
\hline$\geq 4 \mathrm{~h}$ & $163(10.0)$ & $75(5.9)$ & $238(8.2)$ & $<0.001$ \\
\hline Mean (SD), h & $1.42(1.3)$ & $1.12(1.1)$ & $1.28(1.2)$ & \\
\hline \multicolumn{5}{|l|}{ Videogames } \\
\hline $0-1 \mathrm{~h}$ & 1531 (93.7) & $723(56.2)$ & $2254(77.2)$ & \\
\hline $2-3 \mathrm{~h}$ & $50(3.1)$ & $292(22.7)$ & $342(11.7)$ & \\
\hline$\geq 4 \mathrm{~h}$ & $53(3.2)$ & $271(21.1)$ & $324(11.1)$ & $<0.001$ \\
\hline Mean (SD), h & $0.4(1.1)$ & $1.93(1.8)$ & $1.08(1.6)$ & \\
\hline \multicolumn{5}{|l|}{ Screen time\$ } \\
\hline Mean (SD), h & $1.5(01.0)$ & $1.6(1.0)$ & $1.55(1.0)$ & \\
\hline \multicolumn{5}{|l|}{ Bullying } \\
\hline \multicolumn{5}{|l|}{ Bullying } \\
\hline Victims & $728(43.7)$ & $502(38.4)$ & $1230(41.4)$ & 0.004 \\
\hline Authors & $551(33.1)$ & $628(48.4)$ & 1179 (39.8) & $<0.001$ \\
\hline
\end{tabular}

Physical 
Table 1 Characteristics of students according to gender (Continued)

\begin{tabular}{|c|c|c|c|c|}
\hline & $\begin{array}{l}\text { Females } \\
\text { n (\%) }\end{array}$ & $\begin{array}{l}\text { Males } \\
\text { n (\%) }\end{array}$ & $\begin{array}{l}\text { All } \\
n(\%)\end{array}$ & $p$ value $^{a}$ \\
\hline Victims & $78(4.7)$ & $120(9.2)$ & $198(6.7)$ & $<0.001$ \\
\hline Authors & $99(6.0)$ & $240(18.8)$ & $339(11.5)$ & $<0.001$ \\
\hline \multicolumn{5}{|l|}{ Psychological } \\
\hline Victims & 637 (38.6) & $378(29.1)$ & $1015(34.4)$ & $<0.001$ \\
\hline Authors & $445(26.8)$ & $379(29.6)$ & $824(28.1)$ & 0.095 \\
\hline \multicolumn{5}{|l|}{ School climate } \\
\hline Negative perception & $567(33.8)$ & $415(31.4)$ & $982(32.7)$ & 0.172 \\
\hline \multicolumn{5}{|l|}{ Mental health evaluation } \\
\hline \multicolumn{5}{|l|}{ CES-DC scale } \\
\hline Depressive symptoms & $432(28.7)$ & $119(10.4)$ & $551(20.8)$ & $<0.001$ \\
\hline Mean (SD) & $22.50(12.8)$ & $14.86(10.9)$ & $19.20(12.6)$ & $<0.001$ \\
\hline \multicolumn{5}{|l|}{ SDQ scale, overall } \\
\hline Mean (SD) & $14.62(6.1)$ & $12.01(6.0)$ & $13.48(6.2)$ & $<0.001$ \\
\hline Symptoms of mental health problems & $366(22.3)$ & $155(12.1)$ & $521(17.8)$ & $<0.001$ \\
\hline \multicolumn{5}{|l|}{ SDQ scale, internalizing subscale } \\
\hline Internalizing symptoms & $580(35.1)$ & $207(16.1)$ & $787(26.7)$ & $<0.001$ \\
\hline Mean (SD) & $7.23(3.8)$ & $4.96(3.6)$ & $6.24(3.9)$ & $<0.001$ \\
\hline \multicolumn{5}{|l|}{ SDQ scale, externalizing subscale } \\
\hline Externalizing symtoms & $326(19.7)$ & $211(16.3)$ & $537(18.2)$ & 0.020 \\
\hline Mean (SD) & $7.4(3.5)$ & $7.1(3.5)$ & $7.3(3.5)$ & 0.005 \\
\hline
\end{tabular}

${ }^{a} \mathrm{p}$ value refers to $\mathrm{x} 2$ test or test for linear trend of the log-odds for categorical variables and Wilcoxon rank test for continuous variables

\$Total time spent in TV, social networks, web navigation, or videogames

${ }^{\S}$ Tobacco or alcohol use or perception: at least once in previous month

symptoms of mental health problems was higher among Naples than Brescia students (32.4\% vs $26.5 \%$ for CESDC). More students from Brescia than Naples reported substance use: for tobacco smoking only among males (females $33.1 \%$ vs $28.9 \%$; males $31.2 \%$ vs $24.2 \%$ ) and for alcohol consumption in both genders (females $39.1 \%$ vs 29.7\%; males $48.4 \%$ vs $42.0 \%$ ). More girls from Brescia than from Naples reported active bullying (36.2 and $27.7 \%$, respectively). Using social network for more than $6 \mathrm{~h}$ per day was more frequent among Naples than Brescia students in both females (46.6\% vs $21.9 \%)$ and males (23.8\% vs $7.3 \%)$.

The associations between depressive symptoms (CESDC score) and risk factors are shown in Table 2. Tobacco and alcohol use, screen time, physical and psychological bullying, and negative school climate perception were associated with depressive symptoms with ORs ranging from 1.2 to 3.3. Among the technology devices, stronger associations with symptoms of mental health problems were found for TV and social network use than web navigation and videogame. The OR estimates did not change substantially from unadjusted to adjusted models. Similar associations were found in both males and females, when considered separately (Supplementary Tables 2 and 3).

Accordingly, the same variables were associated with symptoms of mental health problems according to SDQ score (Table 3), with OR estimates ranging from 1.3 to 5.0. The strongest association was observed for being a victim of physical bullying (ORs from 4.5 to 5.0 ). Yet, no substantial differences were found adjusting for covariates. Similar results were observed when stratifying for gender, apart from a moderately stronger association between physical bullying and symptoms of mental health problems among females than males (OR 5.5 vs 3.4). (Supplementary Tables 4 and 5).

\section{Discussion}

The main result of this study was the relatively high proportion of 15-16 years old adolescents with symptoms of mental health problems at screening questionnaires, higher in girls than in boys, particularly regarding internalizing symptoms. About one-third of the students claimed to have smoked tobacco and almost half of males had consumed alcohol in the past month. Several students spent a long time on social networks every day, 
Table 2 Number and proportion of students with, and odds ratio for, depressive symptoms on CES-DC according to behavioral factors and school climate perception

\begin{tabular}{|c|c|c|c|c|c|}
\hline \multicolumn{2}{|l|}{ Independent variables } & n (\%) & $\begin{array}{l}\text { Unadjusted models } \\
\text { OR }(95 \% \mathrm{Cl})\end{array}$ & $\begin{array}{l}\text { Adjusted models A } \\
\text { OR }(95 \% \mathrm{Cl})\end{array}$ & $\begin{array}{l}\text { Adjusted models B } \\
\text { OR }(95 \% \mathrm{Cl})\end{array}$ \\
\hline \multicolumn{6}{|l|}{ Gender } \\
\hline Females & & $432(28.7)$ & 1 & 1 & 1 \\
\hline Males & & $119(10.4)$ & $0.3(0.2,0.4)$ & $0.3(0.3,0.4)$ & $0.3(0.3,0.4)$ \\
\hline \multicolumn{6}{|l|}{ Higher parental education, years } \\
\hline$\leq 8$ & & $80(21.7)$ & 1 & 1 & 1 \\
\hline $9-13$ & & $238(20.1)$ & $0.9(0.7,1.2)$ & $1.0(0.8,1.4)$ & $1.0(0.7,1.4)$ \\
\hline$\geq 14$ & & $207(20.5)$ & $0.9(0.7,1.2)$ & $1.3(0.9,1.7)$ & $1.3(0.9,1.7)$ \\
\hline \multicolumn{6}{|l|}{ Substance use } \\
\hline \multirow[t]{2}{*}{ Tobacco smoking } & No & $311(17.0)$ & 1 & 1 & 1 \\
\hline & Yes & $240(29.1)$ & $2.0(1.6,2.4)$ & $1.8(1.5,2.3)$ & $1.9(1.5,2.3)$ \\
\hline \multirow[t]{2}{*}{ Perceived tobacco dependence } & No & $399(17.7)$ & 1 & 1 & 1 \\
\hline & Yes & $126(36.2)$ & $2.6(2.1,3.4)$ & $2.2(1.7,2.9)$ & $2.3(1.7,3.0)$ \\
\hline \multirow[t]{2}{*}{ Alcohol consumption } & No & $299(19.4)$ & 1 & 1 & 1 \\
\hline & Yes & $244(22.7)$ & $1.2(1.0,1.5)$ & $1.4(1.1,1.7)$ & $1.4(1.1,1.7)$ \\
\hline \multirow[t]{2}{*}{ Perceived drunkenness } & No & $477(20.0)$ & 1 & 1 & 1 \\
\hline & Yes & $56(29.2)$ & $1.6(1.2,2.3)$ & $1.9(1.3,2.7)$ & $1.9(1.3,2.8)$ \\
\hline \multicolumn{6}{|l|}{ Screen time } \\
\hline \multicolumn{6}{|l|}{ TV } \\
\hline $0-3 h$ & & $382(18.0)$ & 1 & 1 & 1 \\
\hline$\geq 4 h$ & & $157(32.7)$ & $2.2(1.8,2.8)$ & $1.9(1.5,2.5)$ & $1.9(1.5,2.4)$ \\
\hline \multicolumn{6}{|l|}{ Social networks } \\
\hline $0-3 h$ & & $207(14.4)$ & 1 & 1 & 1 \\
\hline $4-5 \mathrm{~h}$ & & $145(24.5)$ & $1.9(1.5,2.4)$ & $1.5(1.1,1.9)$ & $1.4(1.1,1.8)$ \\
\hline$\geq 6 \mathrm{~h}$ & & 188 (31.9) & $2.8(2.2,3.5)$ & $1.9(1.4,2.4)$ & $1.8(1.3,2.3)$ \\
\hline \multicolumn{6}{|l|}{ Web navigation } \\
\hline $0-3 h$ & & $472(19.8)$ & 1 & 1 & 1 \\
\hline$\geq 4 \mathrm{~h}$ & & $67(32.4)$ & $1.9(1.4,2.6)$ & $1.6(1.1,2.2)$ & $1.5(1.1,2.1)$ \\
\hline \multicolumn{6}{|l|}{ Videogames } \\
\hline $0-3 \mathrm{~h}$ & & $490(21.1)$ & 1 & 1 & 1 \\
\hline$\geq 4 \mathrm{~h}$ & & $48(17.0)$ & $0.8(0.5,1.1)$ & $1.3(0.9,1.9)$ & $1.2(0.8,1.8)$ \\
\hline \multicolumn{6}{|l|}{ Bullying } \\
\hline \multicolumn{6}{|l|}{ Bullying } \\
\hline \multirow[t]{2}{*}{ Victims } & No & $207(13.5)$ & 1 & 1 & 1 \\
\hline & Yes & $340(30.6)$ & $2.8(2.3,3.4)$ & $2.7(2.2,3.4)$ & $2.7(2.2,3.4)$ \\
\hline \multirow[t]{2}{*}{ Author } & No & $305(19.3)$ & 1 & 1 & 1 \\
\hline & Yes & $240(22.7)$ & $1.2(1.0,1.5)$ & $1.2(1.0,1.5)$ & $1.2(1.0,1.5)$ \\
\hline \multicolumn{6}{|l|}{ Physical bullying } \\
\hline \multirow[t]{2}{*}{ Victims } & No & $476(19.4)$ & 1 & 1 & 1 \\
\hline & Yes & $64(37.0)$ & $2.4(1.8,3.4)$ & $3.2(2.2,4.7)$ & $3.3(2.3,4.7)$ \\
\hline \multirow[t]{2}{*}{ Author } & No & $471(20.3)$ & 1 & 1 & 1 \\
\hline & Yes & $63(21.4)$ & $1.1(0.8,1.4)$ & $1.3(1.0,1.9)$ & $1.4(1.0,1.9)$ \\
\hline
\end{tabular}

Psychological bullying 
Table 2 Number and proportion of students with, and odds ratio for, depressive symptoms on CES-DC according to behavioral factors and school climate perception (Continued)

\begin{tabular}{|c|c|c|c|c|c|}
\hline Independent variables & & n (\%) & $\begin{array}{l}\text { Unadjusted models } \\
\text { OR }(95 \% \mathrm{Cl})\end{array}$ & $\begin{array}{l}\text { Adjusted models A } \\
\text { OR }(95 \% \mathrm{Cl})\end{array}$ & $\begin{array}{l}\text { Adjusted models B } \\
\text { OR }(95 \% \mathrm{Cl})\end{array}$ \\
\hline \multirow[t]{2}{*}{ Victims } & No & $271(15.9)$ & 1 & 1 & 1 \\
\hline & Yes & $269(29.0)$ & $2.2(1.8,2.6)$ & $2.0(1.6,2.4)$ & $2.0(1.6,2.5)$ \\
\hline \multirow[t]{2}{*}{ Author } & No & $365(19.5)$ & 1 & 1 & 1 \\
\hline & Yes & $169(22.5)$ & $1.2(1.0,1.5)$ & $1.1(0.9,1.3)$ & $1.1(0.9,1.4)$ \\
\hline \multicolumn{6}{|l|}{ School climate } \\
\hline Positive perception & & $293(16.4)$ & 1 & 1 & 1 \\
\hline Negative perception & & $258(29.7)$ & $2.2(1.8,2.6)$ & $1.9(1.6,2.4)$ & $2.0(1.6,2.5)$ \\
\hline
\end{tabular}

Models A: adjusted for tobacco smoking, social networks use, bullying victimization, parental education, and sex Models B: multilevel regression models for institutes and centers adjusted as Models A

and more than $40 \%$ of students said to have been victims or authors of bullying in the past 6 months. Finally, substance use, particularly tobacco smoking, screen time, and bullying were all associated independently with an increased odds of symptoms of mental health problems for both CES-DC and SDQ scales. Associations were in the same direction also stratifying by sex.

Differences in study design, population characteristics, instruments used for defining mental health problems, and study period may challenge comparisons. The findings of some recent studies which assessed depressive or emotional symptom prevalence in 15-16 years old adolescents are reported in Table 4. Findings similar to ours were reported in the Swedish Kupol study, which was carried out using the same questionnaires and study design [13]. The Italian PRISMA study reported a lower proportion of subjects with mental symptoms but it was carried out in younger subjects, used different tools, and collected data from questionnaires filled out by children's parents [18]. The European multicenter study SEYLE reported the prevalence of emotional problems evaluated through SDQ in various countries, including Italy [19]. It showed a lower prevalence of emotional problems $(11.8 \%)$ compared to the prevalence of internalizing symptoms scale found in our study (26.7\%). A higher prevalence of depressive problems and unemployment among adults in Naples area may explain the higher prevalence of mental health symptoms among adolescents in Naples than Brescia in our study [12].

Tobacco smoking and alcohol consumption prevalence rates in the present study (see Table 1) are not far from those observed in two large studies carried out among Italian children in 2015-2018. In fact, students who had smoked at least one cigarette in the past month were $40 \%$ and $35 \%$ in the ESPAD study [20], Italian participants (mean age 15.2 years, $n=4059$ ), and $31.9 \%$ and $24.8 \%$ in the HBSC study [21] (mean age 15 years, $\mathrm{n}=$ 18918), in females and males, respectively. Students who had drunk at least one alcoholic beverage in the past month were $53 \%$ and $60 \%$ in the ESPAD study [20] for Italian participants, and $45.2 \%$ and $53.5 \%$ in the HBSC study [21], in females and males, respectively. Instead, a much lower prevalence of tobacco smoking and alcohol drinking was found in the Kupol study, probably depending on the restrictive national policy for substance use in Sweden, which is one of the countries with the lowest proportion of tobacco and alcohol users in adults in Europe at present [22].

In line with the literature, not only females showed a higher prevalence of depressive and internalizing symptoms than males $[23,24]$, but also had a higher prevalence of factors associated with symptoms of mental health problems as tobacco smoking, screen time, and physical and psychological bullying victimization.

Among factors associated with depression and other mental health problems, an association of tobacco smoking and alcohol consumption with mental health problems in adolescence has been observed in most studies $[4,5]$. This association should be considered bidirectional: tobacco smoking and alcohol drinking may be facilitated by depressive symptoms as a coping mechanism $[25,26]$, but these substances have also a wellrecognized biological effect on the maturating adolescent's brain and may influence the subsequent development of depression [27, 28].

The school environment has a deep influence on students' behavior and well-being and a relationship between students' perception of the school context and their mental health has been recognized [6, 7]. Both disruptive environments characterized by physical and psychological bullying and competitive environments with high academic standards may impact students' wellbeing and development leading to symptoms of mental health problems. In the present study, we found an association between students' perception of unsatisfying school climate and symptoms of mental health problems, unlike the Kupol study that found the association only for teachers-perceived school climate [29]. 
Table 3 Number and proportion of students with, and odds ratio for, symptoms of mental health problems on SDQ according to behavioral factors and school climate perception

\begin{tabular}{l} 
Independent variables \\
\hline Gender \\
Males \\
Females \\
Higher parental education, years \\
$\leq 8$ \\
$9-13$ \\
$\geq 14$
\end{tabular}

\section{Substance use}

Tobacco smoking
Perceived tobacco dependence
Alcohol consumption
Perceived drunkenness

$\begin{array}{lll}\text { No } & 301(14.8) & 1 \\ \text { Yes } & 220(24.6) & 1.9(1.5,2.3) \\ \text { No } & 382(15.4) & 1 \\ \text { Yes } & 120(32.3) & 2.6(2.1,3.3) \\ \text { No } & 277(16.2) & 1 \\ \text { Yes } & 232(19.9) & 1.3(1.1,1.6) \\ \text { No } & 451(17.1) & 1 \\ \text { Yes } & 48(23.8) & 1.5(1.1,2.1)\end{array}$

Unadjusted models

OR $(95 \% \mathrm{Cl})$

$155(12.1)$

366 (22.3)

$0.5(0.4,0.6)$

94 (22.7)

198 (15.1)

1

$200(18.3)$

$0.6(0.5,0.8)$

$0.8(0.6,1.0)$

$1.5(1.1,2.1)$

\section{Screen time}

TV

$$
\text { 0-3 h }
$$

$\geq 4 \mathrm{~h}$

Social networks

$$
\begin{aligned}
& \text { 0-3 h } \\
& 4-5 h \\
& \geq 6 h
\end{aligned}
$$

Web navigation

$$
\begin{aligned}
& 0-3 \mathrm{~h} \\
& \geq 4 \mathrm{~h}
\end{aligned}
$$

Videogames

$$
\text { 0-3 h }
$$$$
\geq 4 \mathrm{~h}
$$

\section{Bullying}

Bullying

$$
\text { Victims }
$$

Author

Physical bullying

Victims

Author

No

Yes

186 (10.9)

328 (27.2)

1

236 (13.4)

277 (24.0)

$3.1(2.5,3.7)$

Yes

1

$2.0(1.7,2.5)$

$420(15.6) \quad 1$

$88(45.4) \quad 4.5(3.3,6.1)$

$409(16.0) \quad 1$

No

Yes
Adjusted models A OR $(95 \% \mathrm{Cl})$

1

$0.6(0.4,0,7)$

$0.6(0.5,0.8)$

$1.0(0.7,1.3)$

1

$1.7(1.3,2.1)$

1

$2.4(1.8,3.2)$

1

$1.3(1.1,1.6)$

1

$1.5(1.0,2.2)$
$0.6(0.4,0.7)$

$0.6(0.5,0.9)$

$1.0(0.7,1.4)$

Adjusted models B OR $(95 \% \mathrm{Cl})$

1

$1.7(1.4,2.1)$

1

$2.4(1.9,3.2)$

1

$1.4(1.1,1.7)$

1

$1.5(1.0,2.2)$
1

$2.4(1.9,3.1)$

1

$1.4(1.1,1.8)$

$2.2(1.7,2.9)$

1

$1.9(1.4,2.7)$

1

$1.8(1.3,2.6)$
$2.3(1.8,3.0)$

$1.3(1.0,1.8)$

$2.1(1.6,2.7)$

1

$1.8(1.3,2.4)$

$1.7(1.2,2.4)$

Psychological bullying 
Table 3 Number and proportion of students with, and odds ratio for, symptoms of mental health problems on SDQ according to behavioral factors and school climate perception (Continued)

\begin{tabular}{|c|c|c|c|c|c|}
\hline Independent variables & & n (\%) & $\begin{array}{l}\text { Unadjusted models } \\
\text { OR }(95 \% \mathrm{Cl})\end{array}$ & $\begin{array}{l}\text { Adjusted models A } \\
\text { OR }(95 \% \mathrm{Cl})\end{array}$ & $\begin{array}{l}\text { Adjusted models B } \\
\text { OR }(95 \% \mathrm{Cl})\end{array}$ \\
\hline \multirow[t]{2}{*}{ Victims } & No & $274(14.4)$ & 1 & 1 & 1 \\
\hline & Yes & $234(23.5)$ & $1.8(1.5,2.2)$ & $1.9(1.5,2.3)$ & $1.9(1.5,2.3)$ \\
\hline \multirow[t]{2}{*}{ Author } & No & $328(15.9)$ & 1 & 1 & 1 \\
\hline & Yes & $177(21.8)$ & $1.5(1.2,1.8)$ & $1.4(1.1,1.7)$ & $1.4(1.1,1.8)$ \\
\hline \multicolumn{6}{|l|}{ School climate } \\
\hline Positive perception & & $283(14.4)$ & 1 & 1 & 1 \\
\hline Negative perception & & $238(24.7)$ & $1.9(1.6,2.4)$ & $1.7(1.4,2.1)$ & $1.8(1.4,2.2)$ \\
\hline
\end{tabular}

Models A: adjusted for tobacco smoking, social networks use, bullying victimization, parental education, and sex Models B: multilevel regression models for institutes and centers adjusted as Models $A$

Although similar associations have been observed between the other risk factors investigated and students' mental health in the Kupol and Be-Teen study, the apparent discrepancy may be explained by differences in organization and educational methods. Future prospective studies should aim to unravel the underlying pattern that links school climate and mental health problems among adolescents.

The widespread use of technology tools during leisure time by adolescents, particularly social media, has arisen concern as regards the risk of mental health problems. Our findings are in agreement with some recent studies showing an association between digital technology use and depression $[11,30,31]$. However, other studies found only a weak association between digital technology use and adolescent well-being [32]. Despite plenty of epidemiologic studies, the overall evidence of an association between screen time and symptoms of mental health problems is still uncertain: among 7 systematic reviews (3 meta-analyses) that selected 11-70 studies and 5582-46,015 participants, only 2 reported significant associations between social media and depressive symptoms [33]. The type of screen time may play also a main role. In the present study, we found that time spent on TV and social media was more strongly associated with symptoms of mental health problems than web navigation and playing videogames, similarly to findings from other studies [10,31]. Overall, these results suggest that the effect of screen time on adolescents' mental wellbeing depends on the type and content: it is more explained by the "upward social comparison" (screen time users compare themselves with images of "perfect" individuals) and "reinforcing spirals" (screen time users seek information confirming their depressive status) hypotheses than by the "displacement hypothesis" (screen time displaces time participating in healthier activities [10].

Bullying is one of the most common expressions of violence by peers in the school context [34]. The prevalence rates of bullying vary widely across studies, according to its definition, time period, gender, age, social context, and other variables [34]. Prevalence rates of $35 \%$ for bullying perpetration and 36\% for bullying

Table 4 Prevalence of depressive symptoms and symptoms of mental health problems among adolescents in the Be Teen and other surveys

\begin{tabular}{|c|c|c|c|c|}
\hline & Be Teen & Kupol & SEYLE-Europe & PrISMA \\
\hline Year of the survey & 2018 & $2013-2015$ & 2009-2010 & 2007 \\
\hline Area involved & Italy & Sweden & Italy & Italy \\
\hline Number of participants & 3001 & 3349 & 1192 & 3418 \\
\hline Age of participants & $15-16$ & $15-16$ & $13-17$ & $10-14$ \\
\hline \multicolumn{5}{|c|}{ Questionnaire score indicative of mental symptoms/problems } \\
\hline Total & $\begin{array}{l}\text { SDQ: } 17.8 \% \\
\text { CES-DC: } 20.8 \%\end{array}$ & $\begin{array}{l}\text { SDQ: } 18.5 \% \\
\text { CES-DC: } 15.2 \%\end{array}$ & SDQ: $11.8 \%^{\mathrm{a}}$ & $\begin{array}{l}\text { CBCL: } 9.8 \% \\
\text { DAWBA: } 8.2 \%\end{array}$ \\
\hline Male & $\begin{array}{l}\text { SDQ: } 12.1 \% \\
\text { CES-DC:10.4\% }\end{array}$ & $\begin{array}{l}\text { SDQ: } 12.9 \% \\
\text { CES-DC: } 4.8 \%\end{array}$ & & \\
\hline Female & $\begin{array}{l}\text { SDQ: } 22.3 \% \\
\text { CES-DC: } 28.7 \%\end{array}$ & $\begin{array}{l}\text { SDQ: } 23.6 \\
\text { CES-DC: } 24.6 \%\end{array}$ & & \\
\hline
\end{tabular}

${ }^{a}$ Emotional problems. PrISMA Progetto Italiano Salute Mentale Adolescenti [Italian Project on Adolescents' Mental Health] 
victimization were estimated in a meta-analysis of 80 studies that reported similar prevalence rates for cyber and traditional bullying and/or aggression in adolescents [35]. Accordingly, we found that about $40 \%$ of students claimed to have been bullying authors or victims, more often psychological than physical bullying, in agreement with another Italian study [36]. We found a strong association between bullying and symptoms of mental health problems at both scales, more for bullying victimization than active bullying, in line with a national, populationbased Australian study showing that adolescents involved in bullying had significantly increased SDQ depression and anxiety scores in all bullying roles and types [37]. Other studies have shown a concurrent association between involvement in bullying and depression in adolescents, although results are not consistent, as the relationship may be influenced by many factors and because depression by itself may predispose adolescents to victimization from bullying [8].

\section{Strengths and limitations}

The main strength of our study is the assessment of the prevalence of depressive symptoms, internalizing and externalizing problems, and their associations with various adolescents' common habits using standardized methods in a relatively large sample of students in two different areas of the country.

For assessing mental health problems, we used two internationally validated tools for screening of symptoms of mental health problems in adolescence, the SDQ and CES-DC. We administered anonymous questionnaires during school time to whole classes to minimize the risk of selection and information biases. Indeed, the high student's response rate and a low proportion of questionnaires discharged support a low risk of selection and information bias. Internal validity was also confirmed by the high values of Cronbach's alpha for both CES-DC and SDQ:

Some limitation should also be acknowledged. The cross-sectional design is the main limitation of our study as it did not allow us to evaluate the direction of the cause-effect relationships. However, prospective cohort studies which aim to assess the associations between some risk-taking behaviors such as substance use and mental health are at risk of selection bias and incorrect answers, as adolescents must provide informed consent for participating in the study and answer to questions of non-anonymous questionnaires. Indeed, in the Kupol study, a selection of participants has occurred with less than 30\% response rate, which may have determined an estimate of the low prevalence of both substance use and depressive symptoms in participating students as compared to the Swedish general population.
Comparing Naples and Brescia areas, the prevalence of tobacco smoking was higher among adults in the former, according to a national survey [12] while it was lower among adolescents in this study. This might be due to possible higher underreporting of tobacco smoking by students in Naples than Brescia area in our study.

Finally, the risk of confounding in evaluating factors associated with mental health in adolescence is of concern, as the underlying causal pathway is complex and includes several factors. In this study, we investigated only some factors of the many possibilities related to mental health problems. Yet, we found that all the main factors assessed in our study were associated with students' mental health problems also considering multivariable models, without substantial changes in the OR estimates. Furthermore, analyses stratified for gender and center yielded similar results. Finally, the prevalences observed in the present study were substantially similar to those of other surveys, supporting for external validity of this study.

\section{Conclusions}

The present study shows a relatively high prevalence of symptoms of mental health problems, particularly in females, and their association with tobacco and alcohol use, screen time, bullying, and school climate in a large sample of Italian 15-16 years old adolescents. These findings highlight the opportunity for preventive interventions at school, since the investigated risk factors for depression and internalizing problems are theoretically modifiable [34]. The present COVID-19 pandemic has produced deep changes in adolescents' habits, particularly social deprivation, with negative consequences on their mental health, as already observed [38]. Therefore, it could be of the highest interest to repeat crosssectional studies on adolescents' mental health, like this one, in the future to investigate the possible changes from before to after the COVID-19 pandemic time.

\section{Abbreviations \\ CES-DC: Center for Epidemiological Studies-Depression Scale for Children; SDQ: Strengths and Difficulties Questionnaire; PESOC: Pedagogical and Social Climate of a school; OR: Odds ratios; Cl: Confidence interval; SD: Standard deviation}

\section{Supplementary Information}

The online version contains supplementary material available at https://doi. org/10.1186/s12199-021-00988-4.

Additional file 1: Supplementary Table 1. Socio-demographic charac teristics, CES-DC and SDQ abnormal scores and risk factors for symptoms of mental health problems of all students, separated between sexes and areas (Brescia and Naples). Supplementary Table 2. Number and proportion of students with, and odds ratio for, depressive symptoms on CES-DC among females according to behavioral factors and school climate perception. Supplementary Table 3. Number and proportion of students with, and odds ratio for, depressive symptom on CES-DC among 
males according to behavioral factors and school climate perception. Supplementary Table 4. Number and proportion of students with, and odds ratio for, symptoms of mental health problems on SDQ among females according to behavioral factors and school climate perception. Supplementary Table 5. Number and proportion of students with, and odds ratio for, symptoms of mental health problems on SDQ among males according to behavioral factors and school climate perception.

\section{Acknowledgements}

We would like to thank the participating adolescents, families, and schools and the executive team of the Be-teen study who made our research possible. In particular, we would like to thank Adelaide Ciampa, Adriana Correra, Daniela Zaniboni, Elena Zanardini, Emanuele Caputi, Francesca Bianchi, Giuseppe Zenoni, Jacopo Roncali, Marco Moneda, Marta Moretti, and Michele Treccani that took part to the data collection. A special thanks to the Kupol study and Prof. Maria Rosaria Galanti for methodological support.

\section{Authors' contributions}

$E R, F D, E C$, and MT conceived and planned the study. EC, IL, and ER were involved in planning and supervised the data collection. AM, SM, FC, and AE took part to the data collection. SM, FC, and AE performed the statistical analyses. ER, FD SM, FC, and AE took the lead in writing the manuscript. ER supervised the overall project. All authors discussed the results and contributed to the final manuscript. All authors read and approved the final manuscript.

\section{Funding}

No funding was received for conducting the Italian BE-TEEN study. Open Access funding provided by Karolinska Institute.

\section{Availability of data and materials}

The dataset analyzed during the current study are not publicly available in agreement with the ethical recommendations but is available from the corresponding author on reasonable request.

\section{Declarations}

\section{Ethics approval and consent to participate}

The present study was approved by the Ethics Review Board of Brescia Province in Italy (Dnr: 2761-04-10-2017). Information regarding the study was provided by the research team. Participants were advised that participation was voluntary and that the survey was anonymous. This research did not entail sensitive information, medical interventions, or drug testing, and the answers can in no way be linked to identifying information about the respondent. Students aged 15 years or older gave consent for participation by completing the questionnaire.

\section{Consent for publication}

Not applicable.

\section{Competing interests}

All authors declare that they have no competing interests.

\section{Author details}

${ }^{1}$ Unit of Hygiene, Epidemiology and Public Health, University of Brescia, v.le Europa, 11, 25121 Brescia, Italy. ${ }^{2}$ Department of Public Health, University of Naples "Federico II", Via S. Pansini, 5, 80131 Naples, Italy. Institute of Advanced Study, University of Warwick, Coventry CV4 7AL, UK. ${ }^{4}$ Fondazione Poliambulanza Istituto Ospedaliero Multispecialistico, via Bissolati, 57, 25124 Brescia, Italy. ${ }^{5}$ Epidemiology and Public Health Intervention Research Group (EPHIR), Department of Global Public Health, Karolinska Institutet, Solnavägen $1 \mathrm{E}, 11365$ Stockholm, Sweden.

Received: 2 April 2021 Accepted: 6 June 2021

Published online: 21 June 2021

\section{References}

1. Global burden of 369 diseases and injuries in 204 countries and territories, 1990-2019: a systematic analysis for the Global Burden of Disease Study 2019. Lancet (London) 2020, 396(10258):1204-1222.
2. GHDX Global Health Data Exchange http://ghdx.healthdata.org/gbd-resultstool. Accessed 3 May 2021.

3. Thapar A, Collishaw S, Pine DS, Thapar AK. Depression in adolescence. Lancet. 2012;379(9820):1056-67.

4. Fluharty M, Taylor AE, Grabski M, Munafò MR. The association of cigarette smoking with depression and anxiety: a systematic review. Nicotine Tobacco Res. 2017;19(1):3-13. https://doi.org/10.1093/ntr/ntw140.

5. Goodman E, Capitman J. Depressive symptoms and cigarette smoking among teens. Pediatrics. 2000;106(4):748-55. https://doi.org/10.1542/peds.1 06.4.748.

6. Brière FN, Pascal S, Dupéré $\mathrm{V}$, Janosz M. School environment and adolescent depressive symptoms: a multilevel longitudinal study. Pediatrics. 2013;131(3): e702-8. https://doi.org/10.1542/peds.2012-2172.

7. Kidger J, Araya R, Donovan J, Gunnell D. The effect of the school environment on the emotional health of adolescents: a systematic review. Pediatrics. 2012;129(5):925-49. https://doi.org/10.1542/peds.2011-2248.

8. Kaltiala-Heino R, Fröjd S. Correlation between bullying and clinical depression in adolescent patients. Adolesc Health Med Ther. 2011;2:37-44.

9. Rettew DC, Pawlowski S. Bullying. Child Adolesc Psychiatr Clin North Am. 2016;25(2):235-42. https://doi.org/10.1016/j.chc.2015.12.002.

10. Boers E, Afzali MH, Newton N, Conrod P. Association of screen time and depression in adolescence. JAMA Pediatr. 2019;173(9):853-9. https://doi. org/10.1001/jamapediatrics.2019.1759.

11. Primack BA, Swanier B, Georgiopoulos AM, Land SR, Fine MJ. Association between media use in adolescence and depression in young adulthood: a longitudinal study. Arch Gen Psychiatry. 2009;66(2):181-8. https://doi.org/1 0.1001/archgenpsychiatry.2008.532.

12. The representative Italian population Passi survey. https://www.epicentro.iss. it/passi/. Accessed 3 May 2021.

13. Galanti MR, Hultin H, Dalman C, Engström K, Ferrer-Wreder L, Forsell Y, et al. School environment and mental health in early adolescence - a longitudinal study in Sweden (KUPOL). BMC Psychiatry. 2016;16(1):243. https://doi.org/1 0.1186/s12888-016-0919-1.

14. Olsson G, von Knorring AL. Depression among Swedish adolescents measured by the self-rating scale Center for Epidemiology StudiesDepression Child (CES-DC). Eur Child Adolesc Psychiatry. 1997;6(2):81-7. https://doi.org/10.1007/BF00566670.

15. Goodman R, Ford T, Simmons H, Gatward R, Meltzer H. Using the Strengths and Difficulties Questionnaire (SDQ) to screen for child psychiatric disorders in a community sample. Bri J Psychiatry. 2000;177(6):534-9. https://doi.org/1 0.1192/bjp.177.6.534

16. Goodman A, Lamping DL, Ploubidis GB. When to use broader internalising and externalising subscales instead of the hypothesised five subscales on the Strengths and Difficulties Questionnaire (SDQ): data from British parents, teachers and children. J Abnormal Child Psychol. 2010;38(8):1179-91. https://doi. org/10.1007/s10802-010-9434-X.

17. Hultin H, Eichas K, Ferrer-Wreder L, Dimitrova R, Karlberg M, Galanti MR. Pedagogical and social school climate: psychometric evaluation and validation of the student edition of PESOC. Scand J Educ Res. 2019;63(4): 534-50. https://doi.org/10.1080/00313831.2017.1415962.

18. Frigerio A, Rucci P, Goodman R, Ammaniti M, Carlet O, Cavolina P, et al. Prevalence and correlates of mental disorders among adolescents in Italy: the PrISMA study. Eur Child Adolesc Psychiatry. 2009;18(4):217-26. https:// doi.org/10.1007/s00787-008-0720-x.

19. Banzer R, Haring C, Buchheim A, Oehler S, Carli V, Wasserman C, et al. Factors associated with different smoking status in European adolescents: results of the SEYLE study. Eu Child Adolesc Psychiatry. 2017;26(11):1319-29. https://doi.org/10.1007/s00787-017-0980-4.

20. ESPAD Report. Results from the European school survey project on alcohol and other drugs. Luxembourg: Office of the European Union; 2015.

21. Sorveglianza HBSC. https://www.epicentro.iss.it/hbsc/hbsc-italia-2018. Accessed 3 May 2021.

22. Centrum för epidemiologi och samhällsmedicin: Folkhälsorapport 2019, Stockholms län 2019.

23. Merikangas KR, He JP, Burstein M, Swanson SA, Avenevoli S, Cui L, et al. Lifetime prevalence of mental disorders in U.S. adolescents: results from the National Comorbidity Survey Replication--Adolescent Supplement (NCS-A). J Am Acad Child Adolesc Psychiatry. 2010;49(10):980-9. https://doi.org/10.101 6/j.jaac.2010.05.017. 
24. Costello EJ, Mustillo S, Erkanli A, Keeler G, Angold A. Prevalence and development of psychiatric disorders in childhood and adolescence. Arch Gen Psychiatry. 2003;60(8):837-44. https://doi.org/10.1001/archpsyc.60.8.837.

25. Raffetti E, Donato F, Forsell Y, Galanti MR. Longitudinal association between tobacco use and the onset of depressive symptoms among Swedish adolescents: the Kupol cohort study. Eur Child Adolesc Psychiatry. 2019; 28(5):695-704. https://doi.org/10.1007/s00787-018-1237-6.

26. Steuber TL, Danner F. Adolescent smoking and depression: which comes first? Addict Behav. 2006;31(1):133-6. https://doi.org/10.1016/j.addbeh.2005. 04.010.

27. Spear LP. The adolescent brain and age-related behavioral manifestations. Neurosci Biobehav Rev. 2000;24(4):417-63. https://doi.org/10.1016/S01497634(00)00014-2.

28. Steinberg L. Cognitive and affective development in adolescence. TiCS. 2005;9(2):69-74.

29. László KD, Andersson F, Galanti MR. School climate and mental health among Swedish adolescents: a multilevel longitudinal study. BMC Public Health. 2019;19(1):1695. https://doi.org/10.1186/s12889-019-8018-0.

30. Trinh L, Wong B, Faulkner GE. The independent and interactive associations of screen time and physical activity on mental health, school connectedness and academic achievement among a population-based sample of youth. J Can Acad Child Adolesc Psychiatry. 2015;24(1):17-24.

31. Twenge JM, Farley E. Not all screen time is created equal: associations with mental health vary by activity and gender. Soc Psychiatry Psychiatr Epidemiol. 2021;56(2):207-17. https://doi.org/10.1007/s00127-020-01906-9.

32. Orben A, Przybylski AK. The association between adolescent well-being and digital technology use. Nat Human Behav. 2019;3(2):173-82. https://doi. org/10.1038/s41562-018-0506-1.

33. Arias-de la Torre J, Puigdomenech E, García X, Valderas JM, Eiroa-Orosa FJ, Fernández-Villa T, et al. Relationship between depression and the use of mobile technologies and social media among adolescents: umbrella review. J Med Internet Res. 2020;22(8):e16388.

34. Menesini E, Salmivalli C. Bullying in schools: the state of knowledge and effective interventions. Psychol Health Med. 2017;22(sup 1):240-53.

35. Modecki KL, Minchin J, Harbaugh AG, Guerra NG, Runions KC. Bullying prevalence across contexts: a meta-analysis measuring cyber and traditional bullying. J Adolesc Health. 2014;55(5):602-11. https://doi.org/10.1016/j.ja dohealth.2014.06.007.

36. Vieno A, Gini G, Santinello M. Different forms of bullying and their association to smoking and drinking behavior in Italian adolescents. J School Health. 2011;81(7):393-9. https://doi.org/10.1111/j.1746-1561.2011. 00607.x.

37. Ford R, King T, Priest N, Kavanagh A. Bullying and mental health and suicidal behaviour among 14- to 15-year-olds in a representative sample of Australian children. Aust N Z J Psychiatry. 2017;51 (9):897-908. https://doi. org/10.1177/0004867417700275.

38. Orben A, Tomova L, Blakemore SJ. The effects of social deprivation on adolescent development and mental health. Lancet Child Adolesc Health. 2020;4(8):634-40. https://doi.org/10.1016/\$2352-4642(20)30186-3.

\section{Publisher's Note}

Springer Nature remains neutral with regard to jurisdictional claims in published maps and institutional affiliations.

Ready to submit your research? Choose BMC and benefit from:

- fast, convenient online submission

- thorough peer review by experienced researchers in your field

- rapid publication on acceptance

- support for research data, including large and complex data types

- gold Open Access which fosters wider collaboration and increased citations

- maximum visibility for your research: over $100 \mathrm{M}$ website views per year

At BMC, research is always in progress.

Learn more biomedcentral.com/submissions 